\title{
Oligomerization of Uukuniemi virus nucleocapsid protein
}

Anna Katz ${ }^{1 * \dagger}$, Alexander N Freiberg ${ }^{2 \dagger}$, Vera Backström ${ }^{1,3,5}$, Axel R Schulz ${ }^{2}$, Angelo Mateos ${ }^{2}$, Liisa Holm³, Ralf F Pettersson ${ }^{4}$, Antti Vaheri ${ }^{1}$, Ramon Flick ${ }^{2,6}$, Alexander Plyusnin ${ }^{1}$

\begin{abstract}
Background: Uukuniemi virus (UUKV) belongs to the Phlebovirus genus in the family Bunyaviridae. As a nonpathogenic virus for humans UUKV has served as a safe model bunyavirus in a number of studies addressing fundamental questions such as organization and regulation of viral genes, genome replication, structure and assembly. The present study is focused on the oligomerization of the UUKV nucleocapsid (N) protein, which plays an important role in several steps of virus replication. The aim was to locate the domains involved in the $\mathrm{N}$ protein oligomerization and study the process in detail.

Results: A set of experiments concentrating on the $\mathrm{N}$ - and C-termini of the protein was performed, first by completely or partially deleting putative N-N-interaction domains and then by introducing point mutations of amino acid residues. Mutagenesis strategy was based on the computer modeling of secondary and tertiary structure of the N protein. The N protein mutants were studied in chemical cross-linking, immunofluorescence, mammalian two-hybrid, minigenome, and virus-like particle-forming assays. The data showed that the oligomerization ability of UUKV-N protein depends on the presence of intact $\alpha$-helices on both termini of the $\mathrm{N}$ protein molecule and that a specific structure in the $\mathrm{N}$-terminal region plays a crucial role in the $\mathrm{N}-\mathrm{N}$ interaction(s). This structure is formed by two $\alpha$-helices, rich in amino acid residues with aromatic (W7, F10, W19, F27, F31) or long aliphatic $(114,124)$ side chains. Furthermore, some of the N-terminal mutations (e.g. I14A, 124A, F31A) affected the $\mathrm{N}$ protein functionality both in mammalian two-hybrid and minigenome assays.

Conclusions: UUKV-N protein has ability to form oligomers in chemical cross-linking and mammalian two-hybrid assays. In mutational analysis, some of the introduced single-point mutations abolished the $\mathrm{N}$ protein functionality both in mammalian two-hybrid and minigenome assays, suggesting that especially the $\mathrm{N}$-terminal region of the UUKV-N protein is essential for the N-N interaction.
\end{abstract}

\section{Background}

Uukuniemi virus (UUKV) belongs to the Phlebovirus genus in the family Bunyaviridae. Some members of the family are important human pathogens, e.g. CrimeanCongo hemorrhagic fever virus, hantaviruses, and Rift Valley fever virus (RVFV) [1]. UUKV was first isolated from ticks in Uukuniemi, Finland, in 1959 [2], and as a non-pathogenic virus for humans [3], UUKV has served as a safe model bunyavirus in a number of studies addressing fundamental questions, e.g. organization and

\footnotetext{
* Correspondence: anna.katz@helsinki.fi

+ Contributed equally

'Department of Virology, Infection Biology Research Program, Haartman Institute, P.O. Box 21, 00014, University of Helsinki, Helsinki, Finland Full list of author information is available at the end of the article
}

regulation of viral genes, structure and assembly [4-7]. Like other Bunyaviridae, UUKV is an enveloped virus with a tripartite RNA genome of negative polarity. The large (L) segment encodes the RNA-dependent RNA polymerase (L protein), and the medium (M) segment encodes two glycoproteins, $G_{N}$ and $G_{C}$. The small (S) segment encodes the nucleocapsid $(\mathrm{N})$ protein and, in positive sense orientation, the non-structural protein [1]. $\mathrm{N}$ protein plays a central role in the replication, transcription and assembly of RNA viruses. In negativestrand RNA viruses (NSRV), including bunyaviruses, both the vRNA and cRNA are encapsidated by the $\mathrm{N}$ protein into a ribonucleoprotein (RNP) complex, which serves as template for transcription and replication of
C Biomed Central

C 2010 Katz et al; licensee BioMed Central Ltd. This is an Open Access article distributed under the terms of the Creative Commons Attribution License (http://creativecommons.org/licenses/by/2.0), which permits unrestricted use, distribution, and reproduction in any medium, provided the original work is properly cited. 
the viral genome [8]. In the course of RNA encapsidation, the $\mathrm{N}$ protein of NSRV forms oligomers.

Among the NSRV, this oligomerization ability has been demonstrated for several viruses, for example Marburg virus (Filoviridae) [9], Sendai virus (Paramyxoviridae) [10], and influenza A virus (Orthomyxoviridae) [11]. In addition, $\mathrm{N}$ protein $3 \mathrm{D}$-structures for four viruses were solved recently - rabies and vesicular stomatitis viruses (Rhabdoviridae) [12,13], Borna disease virus (Bornaviridae) [14], and influenza A virus [15] revealing the oligomerization domains in detail.

The ability of $\mathrm{N}$ protein to oligomerize has also been shown for bunyaviruses in different genera: Bunyamwera virus (BUNV) (Orthobunyavirus) [16], hantaviruses (Hantavirus) $[17,18]$, tomato spotted wilt virus (Tospovirus) [19], and RVFV (Phlebovirus) [20]. Throughout the five genera, the sizes of bunyaviral $\mathrm{N}$ proteins differ from 25 to $30 \mathrm{kDa}$ (orthobunya-, phlebo-, and tospoviruses) to double the size, 48 to $54 \mathrm{kDa}$ (hanta- and nairoviruses). The mode of $\mathrm{N}$ protein oligomerization seems to differ between the genera as well. BUNV-N protein was shown to form dimers, trimers and higher multimers $[16,21]$, and Tula hantavirus $\mathrm{N}$ protein to form oligomers through trimer formation, where the $\mathrm{N}$ terminal coiled-coils are involved [22-25]. These coiledcoiled domain structures have also been solved for two hantaviruses, Sin Nombre virus and Andes hantavirus [26,27]. A head-to-head and tail-to-tail fashion of oligomerization was suggested for both BUNV and Tula hantavirus $\mathrm{N}$ proteins. For RVFV-N protein, dimer formation was suggested, and the $\mathrm{N}-\mathrm{N}$ interacting domain was mapped to the first $71 \mathrm{~N}$-terminal residues [20]. Further details of the oligomerization process remain largely unknown.

In the present study, we focused on the oligomerization of the UUKV-N protein. Our first experiments using the mammalian two-hybrid (M2H) system and chemical cross-linking showed that the UUKV-N protein molecules can interact with each other. The aim was then to locate domains involved in the $\mathrm{N}$ protein oligomerization and to study this process in more detail.

\section{Results}

Analysis of UUKV-N protein in the chemical cross-linking and $\mathrm{M} 2 \mathrm{H}$ assays

To study the $\mathrm{N}$ protein oligomerization, COS-7 cells were transfected with pcDNA-UUKV-N constructs and lysates were treated with the chemical cross-linker, $\mathrm{BS}^{3}$ (Fig. 1). In the absence of $\mathrm{BS}^{3}$, the monomeric form of the $\mathrm{N}$ protein $(\sim 25 \mathrm{kDa})$ was predominant in immunoblotting (Fig. 1, lane 1). In the presence of $\mathrm{BS}^{3}$, the intensity of monomeric band decreased and the dimeric

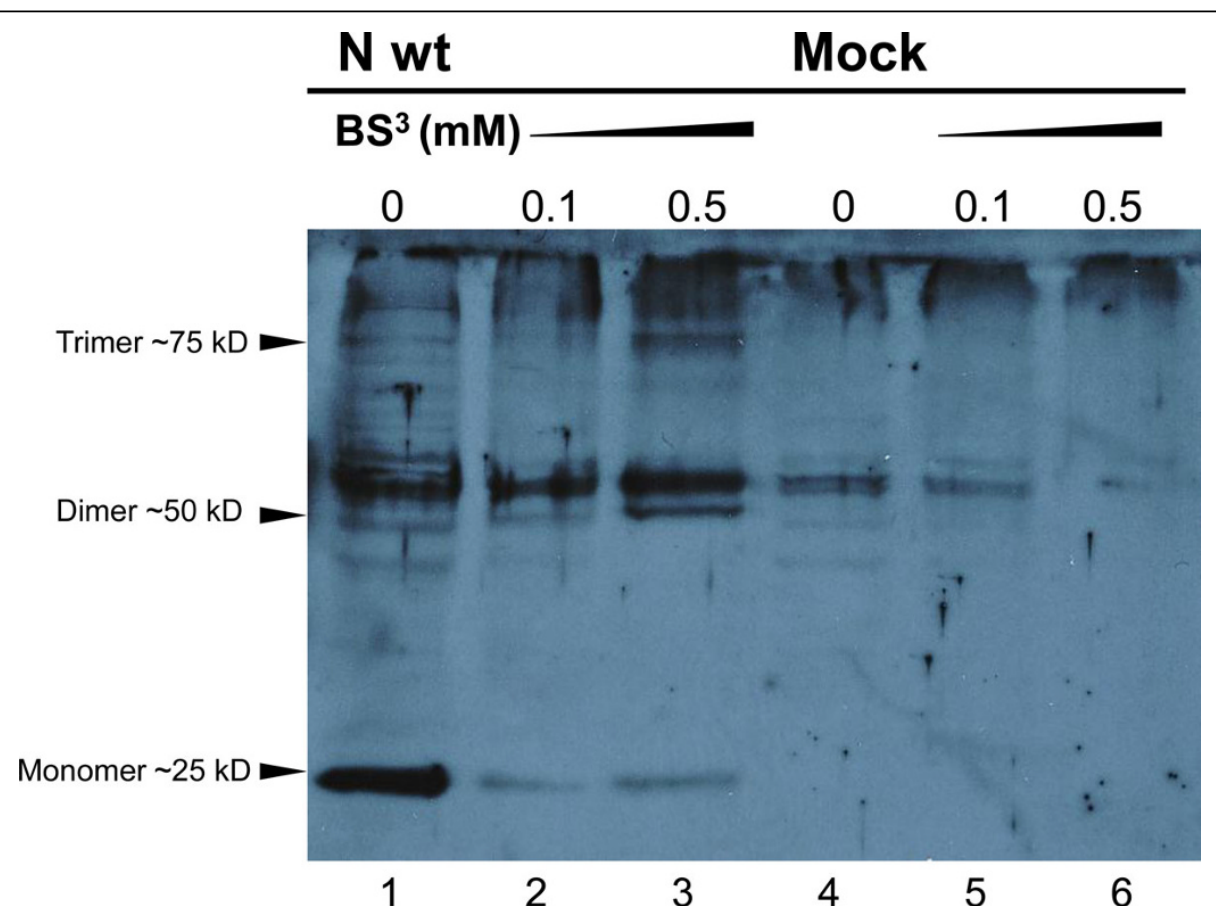

Figure 1 Cross-linking of the UUKV-N protein. N protein containing COS-7 cell lysates were treated with 0.1 or 0.5 mM of cross-linking reagent $\left(\mathrm{BS}^{3}\right)$, and resolved by 10\% SDS-PAGE under denaturing conditions. An immunoblot shows that omitting $\mathrm{BS}^{3}$, the majority of the fulllength UUKV-N protein migrated as $25 \mathrm{kDa}$ monomeric form (lane 1). Addition of $\mathrm{BS}^{3}$ decreased the amount of the monomeric form, while the amount of dimeric and multimeric forms were simultaneously increasing (lanes 2 and 3). In mock-transfected samples no $\mathrm{N}$ protein was detected (lanes 4 to 6 ). 
form $(\sim 50 \mathrm{kDa})$ was formed. In the lysates treated with $0.5 \mathrm{mM}$ of $\mathrm{BS}^{3}$ also a band of $\sim 75 \mathrm{kDa}$ appeared, suggesting the presence of trimers (Fig. 1, lane 3). MOCKtransfected COS-7 cells served as control (Fig. 1, lanes 4 to 6). A band just above the $\mathrm{N}$-dimer as well as the bands that move slower than the $\mathrm{N}$-trimer probably presented unrelated cross-reacting cellular proteins.

These results were in agreement with those obtained using the $\mathrm{M} 2 \mathrm{H}$ assay: UUKV-N protein was expressed as a fusion with the DNA-BD and DNA-AD domains, resulting in high luciferase reporter signal. Same M2H vectors without $\mathrm{N}$ protein inserts served as negative controls, leading to very low signals (data not shown). Thus, both assays clearly demonstrated the $\mathrm{N}$ protein ability to form dimers and higher oligomers.

\section{Secondary and tertiary structure predictions for UUKV-N protein}

For the secondary stucture, Jpred, Psipred and PredictProtein programs predicted the UUKV-N (254 aa residues) to be an $\alpha$-helix-rich protein containing 13 to 15 $\alpha$-helices with one to three short $\beta$-strands. Only minor differences in the length and location of the $\alpha$-helices were observed between these models. In our working model we adopted $13 \alpha$-helices constantly predicted by all used programs (Fig. 2). For the $\mathrm{N}$-terminal region the predictions showed either one long $\alpha$-helix (aa residues 5-33), or two shorter $\alpha$-helices (aa residues 7 19/5-17 and 21-33). In the C-terminal region, two $\alpha$ helices (aa residues 220/221-229/230 and 239/241-252/ 253) were predicted (see $\alpha 1, \alpha 2, \alpha 12$ and $\alpha 13$ in Fig. 2).

Next, the secondary structure predictions for UUKV$\mathrm{N}$ were compared to $\mathrm{N}$ proteins of four other phleboviruses (RVFV, SFSV, TOSV and PTV). Predictions by the Jpred and PsiPred programs showed that the overall secondary structure is well conserved among phleboviruses (data not shown). For the $\mathrm{N}$-terminus, predicted $\alpha$-helices were of the same length ( $\alpha 1: 11-15$ residues; $\alpha 2: 12-13$ residues) and located at similar positions (Fig. $3 \mathrm{~A})$. The same was true for the last C-terminal $\alpha$ helices: $\alpha 13$ and $\alpha 12$ were predicted to be respectively, 11-14 and 10-11 aa residues long, with a short $\beta$-strand located between them. Shorter $\alpha$-helices were predicted within the central part of the molecule, with less uniform pattern than in the well-conserved $\mathrm{N}$ - and C-terminal parts. This analysis suggested that conserved $\alpha-$ helices perform an important, fundamental function shared by all analyzed phleboviral $\mathrm{N}$ proteins.

Tertiary structure of the UUKV-N protein was predicted using Robetta server's ab initio modeling. Altogether, ten models were obtained, one of them is shown in Fig. 3B. All showed the same overall pattern of folding and, in agreement with the secondary structure predictions, contained 13-16 $\alpha$-helices. Similarly to the

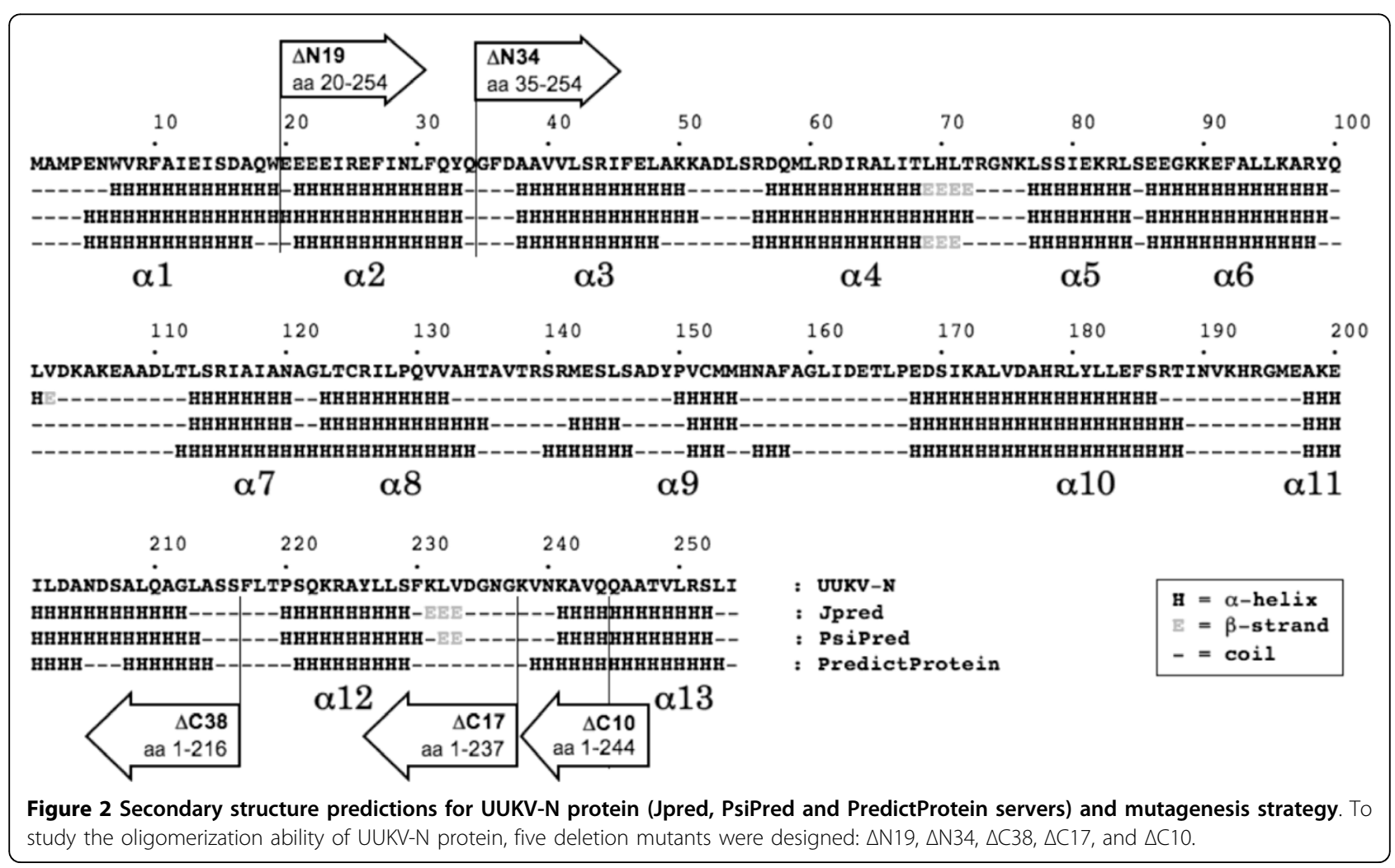




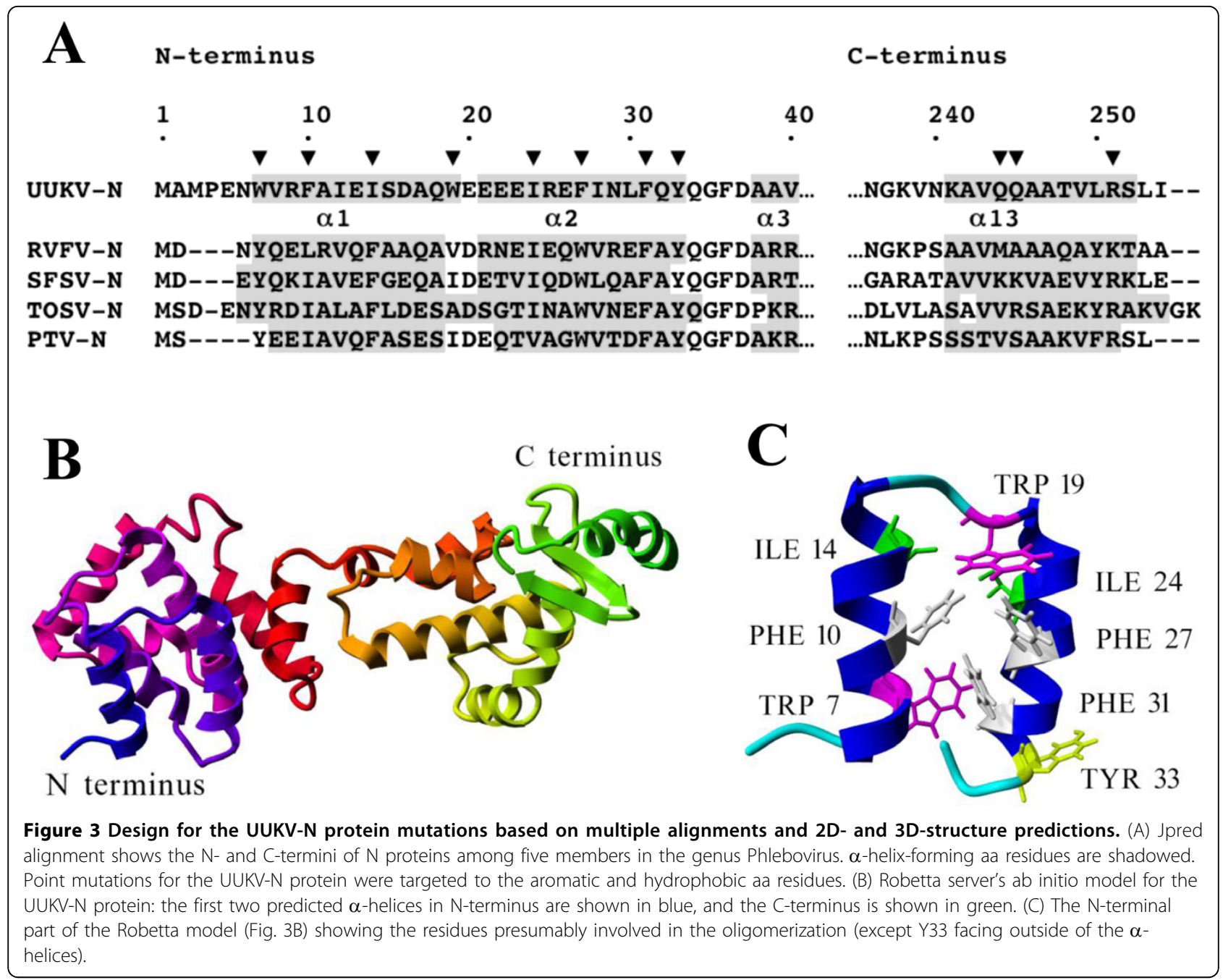

PsiPred prediction, all Robetta models showed two $\alpha$ helices separated by 2-3 aa residues at the $\mathrm{N}$-terminal part of the molecule. At the C-terminal region, two antiparallel $\beta$-strands were predicted (Fig. 3B).

These models of UUKV-N protein were used to define our mutagenesis strategy. Since earlier studies on hantaviruses, RVFV, and BUNV showed that the very terminal regions of the $\mathrm{N}$ protein are especially important for the oligomerization $[16,20,23,25]$, we focused on these regions.

Analysis of the $\mathrm{N}-\mathrm{N}$ interactions in $\mathrm{M} 2 \mathrm{H}$ and minigenome assays

First, predicted $\alpha$-helices were gradually removed from the $\mathrm{N}$ - and $\mathrm{C}$-termini of the $\mathrm{N}$ protein molecule generating five deletion mutants: $\Delta \mathrm{N} 19, \Delta \mathrm{N} 34, \Delta \mathrm{C} 38, \Delta \mathrm{C} 17$, and $\Delta \mathrm{C} 10$ (Fig. 2). In mutant $\Delta \mathrm{N} 19$, the first $\alpha$-helix, and in mutant $\Delta \mathrm{N} 34$, the two first $\alpha$-helices were deleted. Similar strategy was implemented for the C-terminus; in the mutant $\Delta \mathrm{C} 10$, half of the last $\alpha$-helix was removed, in mutant $\Delta \mathrm{C} 17$ the entire last $\alpha$-helix, and in mutant $\Delta$ C38 the last two $\alpha$-helices were deleted (Fig. 2 ). These mutants were tested in the $\mathrm{M} 2 \mathrm{H}$ system, and further studied using the minigenome system, immunofluorescence and cross-linking assays.

In the $\mathrm{M} 2 \mathrm{H}$ system the full-length $\mathrm{N}$ protein showed strong N-N interaction ability (Fig. 4A). This ability decreased in the mutant $\Delta \mathrm{N} 19$, where the remaining activity was only $25 \pm 3 \%$, and totally vanished in the mutant $\Delta$ N34 (Fig. 4A). This effect was repeatedly seen with DNA-AD-fused truncated proteins, even if they reacted with the full-length DNA-BD-N fusion protein. Two constructs, $\triangle N 19-D N A-B D$ and $\triangle$ N34-DNA-BD, showed artificially high signals in the luciferase reporter assay, perhaps due to misfolding of the $\mathrm{N}$ fusion protein. All three C-terminal mutants, $\Delta \mathrm{C} 10$ (Fig. 4A), $\Delta \mathrm{C} 17$ and $\Delta$ C38 (data not shown) were completely non-functional, even if introduced in only one interacting partner (DNA-AD). To exclude the possibility that the lack of reactivity in the $\mathrm{M} 2 \mathrm{H}$ assay was due to inefficient 


\section{A N-N interaction in the $\mathrm{M} 2 \mathrm{H}$ assay (\%)}

DNA-AD

N wt

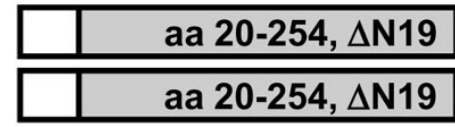

N wt

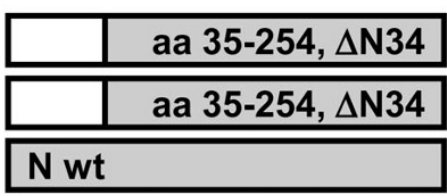

\begin{tabular}{|l|}
\hline aa 1-244, $\Delta \mathrm{C} 10$ \\
\hline aa 1-244, $\Delta \mathrm{C} 10$ \\
\hline $\mathrm{N}$ wt \\
\hline
\end{tabular}

B

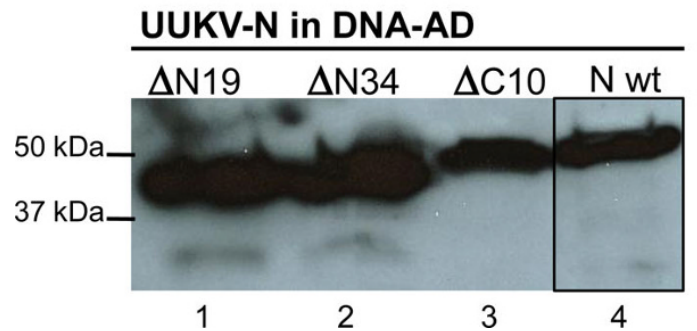

100

N wt

\section{$25 \pm 3$ \\ $20 \pm 4$}

$>100$

\begin{tabular}{|l|r|}
\hline & aa 20-254, $\Delta$ N19 \\
\hline \hline N wt \\
\hline \hline & aa 20-254, $\Delta$ N19 \\
\hline
\end{tabular}

0
0
$>100$

\begin{tabular}{|l|l|}
\hline & aa $35-254, \Delta N 34$ \\
\hline $\mathbf{N} w t$ \\
\hline & aa $35-254, \Delta N 34$ \\
\hline
\end{tabular}

0

0

0

\begin{tabular}{|l|}
\hline aa $1-244, \Delta \mathrm{C} 10$ \\
\hline $\mathrm{N}$ wt \\
\hline aa 1-244, $\Delta \mathrm{C} 10$ \\
\hline
\end{tabular}

UUKV-N in DNA-BD

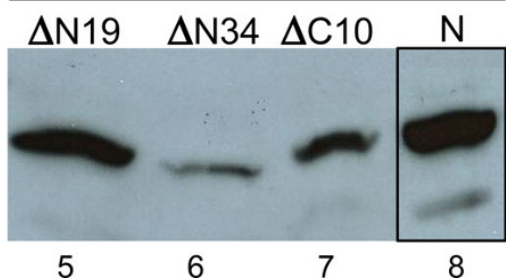

Figure $4 \mathrm{~N}-\mathrm{N}$ interaction of truncated UUKV-N protein constructs in the $\mathrm{M} 2 \mathrm{H}$ assay and verification of the protein expression. (A) Truncation $\triangle N 19$ affected the N-N interaction, $\triangle N 34$ and C-terminal truncation $\triangle C 10$ destroyed the oligomerization ability completely. Deleted regions are shown in white. Numbers are averages of normalized luciferase activity values (\%), where the wt N-N interaction was set as $100 \% . \pm$ standard deviations are calculated for the mean values. (B) $\mathrm{N}$ protein expression of the $\mathrm{M} 2 \mathrm{H}$ constructs was verified in immunoblotting. MAbs were used to detect the N protein fusions with DNA-AD (lanes 1 to 4), and DNA-BD (lanes 5 to 8) constructs, which migrated as 44-46 kDa bands.

protein production, expression levels of truncated $\mathrm{N}$ proteins in COS-7 cells were confirmed by immunoblotting. Even though there was variation in the expression levels, it could not explain the differences in the $\mathrm{M} 2 \mathrm{H}$ results (Fig. 4B).

Deletion mutants were further tested in the UUKV minigenome system. The $\mathrm{N}$ protein molecules supposedly interact with each other and also with viral genome segments and replication intermediates and form RNPs. Interrupting the ability to form $\mathrm{N}$-oligomers should interfere with minigenome transcription and replication. All five $\mathrm{N}$ - and $\mathrm{C}$-terminal deletions completely abolished the function of the $\mathrm{N}$ protein, resulting in a negative CAT signal (Fig. 5). Mutants $\Delta$ N19 and $\triangle \mathrm{C} 10$ were negative in CAT assays; this suggested that both terminal moieties are needed for the oligomerization process. Expression of the UUKV-N mutants was verified by immunofluorescence assay (IFA) (Fig. 6) and by immunoblotting (data not shown). Thus the results obtained with the minigenome system were in agreement with those of the $\mathrm{M} 2 \mathrm{H}$ assay: both $\mathrm{N}$ - and $\mathrm{C}$-terminal $\alpha$-helices are essential for the N-N interactions and even small deletions completely destroyed the protein function (Fig. $4 \mathrm{~A}$ and 5). Furthermore, the results of the cross-linking assay confirmed that all $\mathrm{N}$ - and C-terminal deletions severely affected the ability of $\mathrm{N}$ protein to oligomerize (data not shown). 


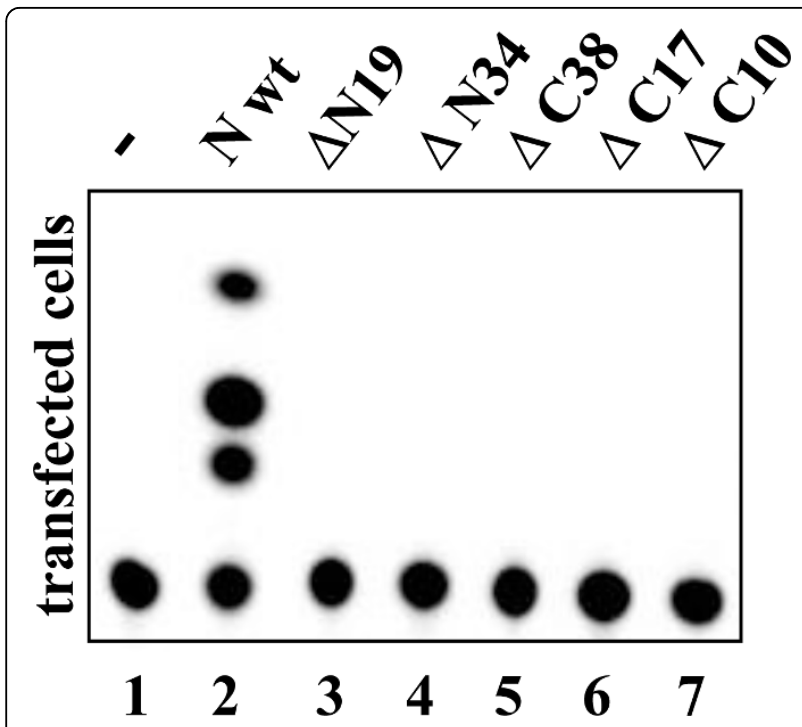

Figure 5 Comparative CAT analysis on $\mathrm{N}$ protein deletion mutants. BHK-21 cells were transfected with UUKV minigenome plasmids: (UUKV M-CAT), viral polymerase expression (pCMV-UUKV-L) and wt or mutant pCDNA-UUKV-N. Cells were analyzed for CAT activity at $48 \mathrm{~h}$ post-transfection. The $\mathrm{N}$ - and C-terminal deletion mutants (lanes 3 to 7) were compared with wt $\mathrm{N}$ protein (lane 2), showing that all the deletion mutants were non-functional in the minigenome system. In the negative control (lane 1) pCMV-UUKV-L was omitted.

\section{Analysis of the intracellular localization and distribution of wt and truncated UUKV-N protein using immunofluorescence assay}

Next, we examined where the wt and truncated UUKV$\mathrm{N}$ protein localizes in transfected cells and whether there are differences in the staining pattern (Fig. 6). Wild type (wt) $\mathrm{N}$ protein localized in the cytoplasm and formed larger aggregates (Fig. 6), resembling UUKVinfected cells (Fig. 6), as also presented earlier [28]. Of the N-terminal truncations, $\Delta \mathrm{N} 19$ did not have a major effect on the appearance of the stained protein aggregates. It resembled the pattern of wt $\mathrm{N}$ protein, although some diffuse staining was observed. However, truncation $\Delta$ N34 differed from the wt $\mathrm{N}$ protein remarkably: the protein was dispersed throughout the cytoplasm as a diffuse net, with only a few microgranular aggregates observed (Fig. 6). In all C-terminal truncations, both intracellular localization and the staining pattern of the $\mathrm{N}$ protein were strongly affected. These truncated $\mathrm{N}$ proteins were dispersed as a diffuse pattern in the cytoplasm, with some small microgranular aggregates similar to mutant $\Delta$ N34. Truncated proteins were also observed in the nuclei, the effect was most pronounced with the longest truncation, $\Delta$ C38 (Fig. 6). Most importantly, no protein aggregates, characteristic of the wt $\mathrm{N}$ protein, were seen.
Bioinformatic analysis and mutagenesis strategy of point mutations

Experiments with truncated UUKV-N proteins directed us to focus on the $\mathrm{N}$ - and $\mathrm{C}$-termini of the molecule, using site-directed mutagenesis to define aa residues involved in the $\mathrm{N}-\mathrm{N}$ interactions. Sequence alignment and secondary structure predictions revealed very few conserved aa residues within the last $\mathrm{C}$-terminal $\alpha$-helix. To check whether this helix is directly involved in the $\mathrm{N}-\mathrm{N}$ interaction(s) two mutations were introduced: $\mathrm{R} 251$, conserved in all phleboviruses (except $\mathrm{K}$ in RVFV), was replaced with alanine, and the double mutant QQ244,245AA, was designed to evaluate the possible role of the polar side chains in the N-N interaction. These mutants did not differ from the wt $\mathrm{N}$ protein in $\mathrm{M} 2 \mathrm{H}$, minigenome and VLP assays (Table 1, Fig. 7, lanes 12 and 13), and also in cross-linking and IFA (data not shown). It seems that the last C-terminal $\alpha$ helix is not directly involved in the oligomerization but is indispensable for maintaining a proper folding of the whole molecule and hence its functional competence. We therefore concentrated on the $\mathrm{N}$-terminal part of the protein.

Most models indicated that the $\mathrm{N}$-terminal region (aa 1-33), forms two $\alpha$-helices separated by a short turn (Fig. 3C). This region is rich with aromatic and hydrophobic residues. In Robetta 3D-model of UUKV-N protein (Fig. 3B and 3C), it was observed that W7, F10, I14, W19, I24, F27 and F31 are facing the same side of a $\alpha$ helical projection of the molecule. This structure with two parallel $\alpha$-helices resembles the $\mathrm{N}$-terminal coiledcoil structure of the hantaviral $\mathrm{N}$ protein that was shown to be important for the $\mathrm{N}-\mathrm{N}$ interactions $[23,25,29]$. The model for UUKV-N protein suggests that the shared hydrophobic space between first two $\alpha$ helices is not exposed to the solvent. After a conformational change opening the structure, the listed aa residues could interact with their partners in the other $\mathrm{N}$ monomer. To evaluate the contribution of these residues to the N-N interaction, and the overall functionality of the $\mathrm{N}$ protein molecule, eight point mutants were generated: W7A, F10A, I14A, W19A, I24A, F27A, F31A, and Y33A (Fig. 3A, arrowheads). Tyrosine at position 33 was facing outside of the $\alpha$-helices, and therefore its replacement with alanine was expected to have no effect on the oligomerization.

\section{Analysis of the $\mathrm{N}$-terminal point mutations in $\mathrm{M} 2 \mathrm{H}$ and minigenome assays}

Eight alanine substitutions were introduced to the $\mathrm{N}$ protein fused with the DNA-BD and DNA-AD for $\mathrm{M} 2 \mathrm{H}$ assay and pcDNA-UUKV-N expression plasmids. In $\mathrm{M} 2 \mathrm{H}$ assay, four mutants, F10A, I14A, I24A, and F31A, 


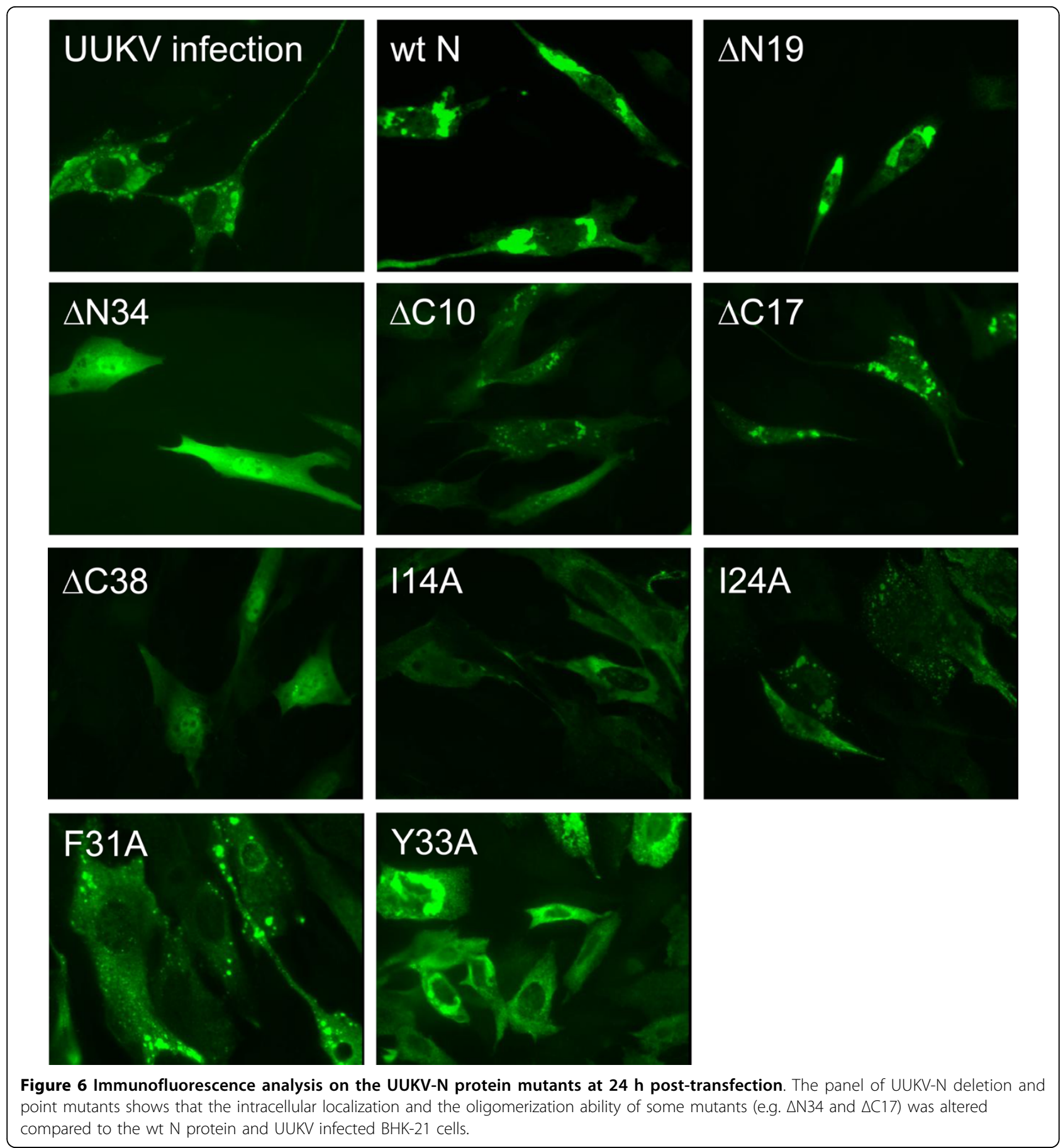

showed a reduced N-N interaction ability. Four other mutations, W7A, W19A, F27A, and Y33A (our negative control), acted as the wt $\mathrm{N}$ protein (Table 1). In the minigenome system, five mutations (W7A, I14A, I24A, F27A, and F31A) completely abolished CAT expression, mutations F10A and W19A had a moderate impact, whereas mutation Y33A did not affect the functionality of the protein (Fig. 7, upper panel, and Table 1).
Expression of all mutants was verified by IFA (Fig. 6) and immunoblotting (data not shown).

Analysis of the point mutations in the virus-like particle (VLP) system

To further test point mutations on the $\mathrm{N}$ protein functional competence, we used recently developed infectious VLP system for UUKV [30], in which cells 
Table 1 Summary of the results: UUKV-N protein point mutants in the M2 $\mathrm{H}$, minigenome, and immunofluorescence assays

\begin{tabular}{llllll}
$\begin{array}{l}\text { UUKV-N protein } \\
\text { point mutants }\end{array}$ & $\begin{array}{l}\text { M2H } \\
\%\end{array}$ of interaction & & Minigenome $^{+}$ & VLP $^{\dagger}$ & IFA $^{*}$ \\
\hline Wt N protein & 100 & +++ & +++ & +++ & +++ \\
W7A & $>100(3)$ & +++ & - & - & +++ \\
F10A & $34 \pm 4(2)$ & + & + & + & +++ \\
I14A & $60 \pm 18(3)$ & ++ & - & - & + \\
W19A & $>100(3)$ & +++ & + ++ & - & + \\
I24A & $56 \pm 12(2)$ & ++ & - & - & + \\
F27A & $>100(3)$ & +++ & - & - & ++ \\
F31A & $23 \pm 5(2)$ & + & - & - & ++ \\
Y33A & $>100(2)$ & +++ & +++ & +++ & +++ \\
QQ244,245AA & $>100(2)$ & +++ & +++ & +++ & +++ \\
R251A & $96 \pm 11(2)$ & +++ & +++ & +++ & +++
\end{tabular}

* Full-length N-N protein interaction $(100 \%,+++)$ was compared to the N-N interaction of point mutants, range from not affected $(+++)$ to reduced $(++)$ and to substantially reduced interaction (+). Each test was performed in triplicates, number of repetitions for each test is given in parentheses.

${ }^{\dagger}$ In minigenome and VLP systems the CAT expression was either non-affected $(+++)$, reduced $(++)$, substantially reduced $(+)$, or completely inhibited (-).

₹ Point mutants forming aggregates resembling full-length $\mathrm{N}$ protein $(+++)$, showing microgranular $(++)$ or diffuse $(+)$ fluorescence pattern. transfected with expression plasmids encoding for $\mathrm{UUKV}-\mathrm{G}_{\mathrm{N}} / \mathrm{G}_{\mathrm{C}}, \mathrm{N}$ protein, and viral polymerase, together with the UUKV minigenome, generate VLPs containing the minigenome. UUK-VLPs are released into the cell supernatant and able to infect new cells. It was assumed that if the $\mathrm{N}$ protein functionality is affected, it would inhibit, or even abolish, both packaging and transfer ability of the minigenome. No CAT activity was detected in the negative control of VLPinfected cells omitting UUKV-L and UUKV- $G_{N} / G_{C}$, respectively (Fig. 7, lower panel, lanes 1 and 2). The positive control containing $U U K V-G_{N} / G_{C}$ showed strong CAT activity (Fig. 7, lower panel, lane 3). Six Nterminal point mutants (W7A, I14A, W19A, I24A, F27A, and F31A) showed reduced CAT signal indicating the affected $\mathrm{N}$ protein ability to oligomerize and/or encapsidate minigenome RNA (Fig. 7 and Table 1).

Three of these mutants, I14A, I24A, and F31A, showed reduced functional competence in the minigenome assay and affected N-N interaction ability in the $\mathrm{M} 2 \mathrm{H}$ assay. In addition, two mutants, W7A and F27A, showed either reduced or totally inhibited functional

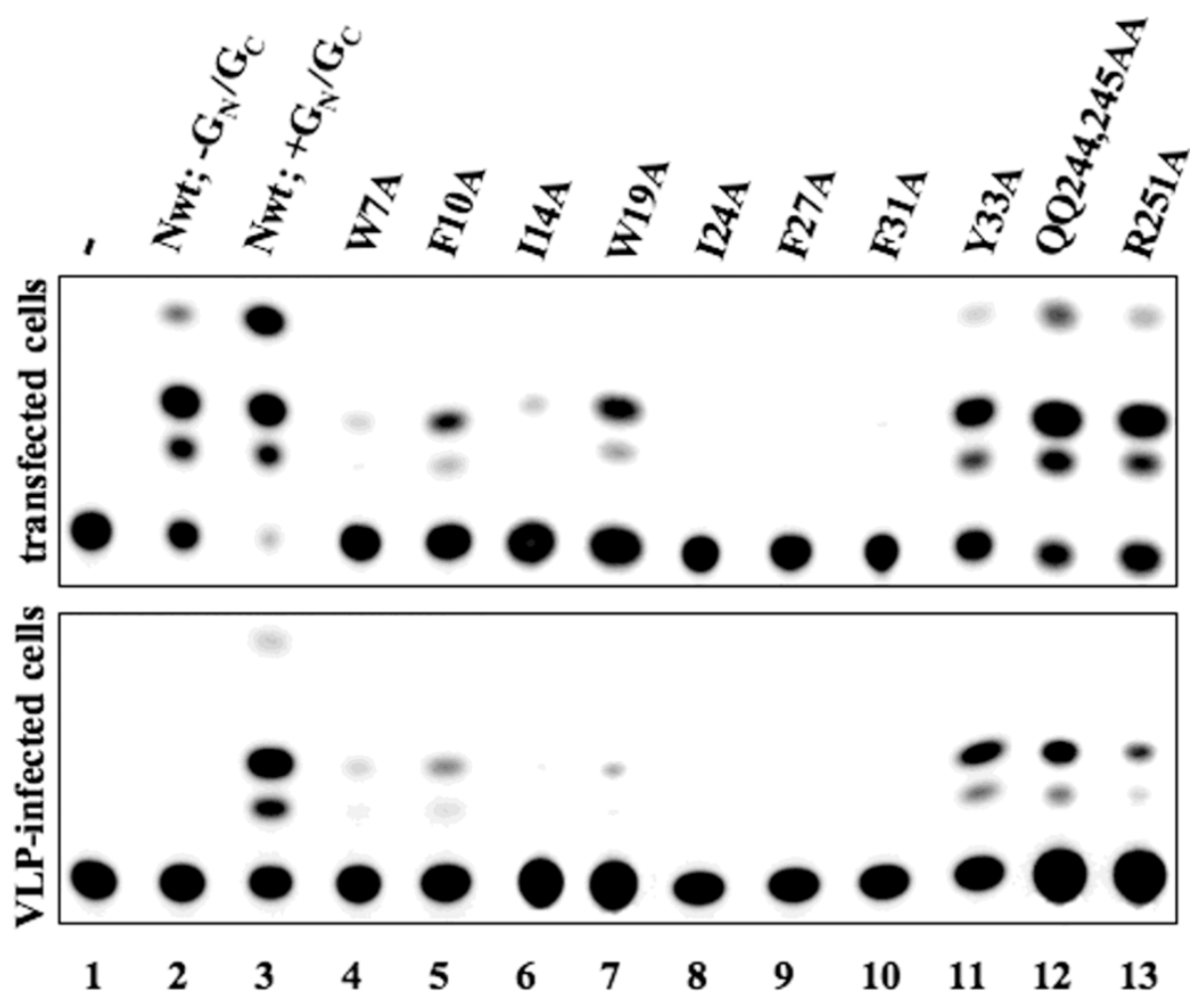

Figure 7 UUKV-N point mutants analyzed by comparative CAT analysis and VLP transfer of UUKV M-CAT minigenome. Upper panel: In comparative CAT analysis, BHK-21 cells were transfected with UUKV M-CAT, pCMV-UUKV-L and wt or mutant pcDNA-UUKV-N plasmids, and the glycoprotein expression plasmid pCMV-UUKV-GN/GC was co-transfected for VLP transfer of the minigenome. Cells were analyzed for CAT activity, and VLP-containing supernatant was used to infect new cells pre-transfected with PCMV-UUKV-L and wt UUKV-N protein. Lower panel: UUKV-N point mutants analyzed by CAT expression and VLP transfer of UUKV M-CAT minigenome. Negative controls omit either pCMV-UUKV-L (lane 1) or include pCMV-UUKV-L but omit PCMV-UUKV- $G_{N} / G_{C}$ (lane 2; negative control for VLP transfer). 
ability in the minigenome assay and in the $\mathrm{M} 2 \mathrm{H}$ assay gave artificially high signals. This discrepancy could indicate on a possible involvement of these residues in RNA-binding. Our control (Y33A) as well as two Cterminal mutants (R251A and QQ244,245AA) acted similarly in the VLP-assay compared to the wt N protein, i.e. were able to encapsidate, package and transfer a functional minigenome. To summarize, the results of the VLP assay were in agreement with the other two tests described above. They also logically showed that the demand for the functional competence of the involved components, including the $\mathrm{N}$ protein, is higher in this more integral system thus fewer alterations are tolerated.

\section{Immunofluorescence microscopy of UUKV-N protein mutants}

All eight $\mathrm{N}$-terminal and two $\mathrm{C}$-terminal point mutations were also tested in IFA. Six mutants, including our negative control and two C-terminal mutants (W7A, F10A, F27A, Y33A, QQ244,245AA, and R251A) behaved as the wt $\mathrm{N}$ protein. They formed aggregates located mostly in the perinuclear region (a typical mutant from this group, Y33A, is shown on Fig 6). In sharp contrast, four other mutants (I14A, W19A, I24A, and F31A) showed a diffuse to microgranular pattern of staining (Fig. 6 and data not shown). These results suggested that at least some of the mutations, which inflicted the $\mathrm{N}-\mathrm{N}$ interactions, also affected the intracellular localization of the $\mathrm{N}$ protein.

Results of different assays are summarized in Table 1. For six mutants the correlation was good. These mutations included those that affected the $\mathrm{N}$ protein functionality (I14A, I24A and F31A), and also the ones inflicting no detectable damage (Y33A, QQ244,245AA, $\mathrm{R} 251 \mathrm{~A})$. The results for other mutations were ambiguous. Mutants W7A and F27A were particularly interesting: although they were capable to interact in the $\mathrm{M} 2 \mathrm{H}$ assay and their IFA-staining pattern was the same as of the wt $\mathrm{N}$ protein, these mutations were not functional in the minigenome assay.

\section{Discussion}

Results presented in this paper show that the molecules of UUKV-N protein molecules can interact with each other. Thus, in this respect, the UUKV-N protein resembles the nucleocapsid proteins of other NSRV [9-14,16-19].

Our experiments revealed that the oligomerization ability of UUKV-N protein depends on the presence of intact $\alpha$-helices on both termini of the molecule. Moreover, the point mutagenesis data in combination with the computer modeling, suggested that a specific structure in the $\mathrm{N}$-terminal region plays a crucial role in the
$\mathrm{N}-\mathrm{N}$ interaction(s). This structure (Fig. 3C) is formed by two $\alpha$-helices, rich in aa residues with aromatic (W7, F10, W19, F27, F31, Y33) or long aliphatic (I14, I24) side chains. Seven of these residues are predicted to face the same side of the $\alpha$-helical structure and presumably form an interacting surface during the oligomerization process. The side chain of Y33 is oriented differently (Fig. 3C) and therefore this residue served as a useful control. Replacement of any of the seven above-mentioned aa residues with alanines significantly reduced the $\mathrm{N}$ protein functionality in at least one of three functional assays: $\mathrm{M} 2 \mathrm{H}$, minigenome or VLP assays and, as expected, the mutation Y33A did not affect the $\mathrm{N}$ protein functionality (Table 1 ). Note that the $\mathrm{M} 2 \mathrm{H}$ assay is best suited for the direct evaluation of the N-N interacting ability, whereas the minigenome and VLP assays are more complex and thus more demanding in terms of functional competence of the $\mathrm{N}$ protein. It should be capable not only to oligomerize but also to interact with the RNA template, the cytoplasmic tail of $G_{N}$ protein and, perhaps with other components of a viral transcription-replication-packaging machinery such as the L protein. This could explain the results observed with mutants W7A and F27A: although they were capable to interact in the $\mathrm{M} 2 \mathrm{H}$ assay and their IFA-staining pattern was the same as that of the wt $\mathrm{N}$ protein, these mutations were not functional in the minigenome assay suggesting that these aa residues might be involved in other functions, for example, RNA binding. Three of these seven mutants (I14A, I24A, and F31A) showed also a changed pattern of the intracellular distribution of $\mathrm{N}$ protein seen in the IFA. This diffuse or microgranular pattern in IFA staining most probably reflected a reduced oligomerization ability of the $\mathrm{N}$ protein molecule (Fig. 6).

Our data correlated well with the earlier observations made for another phlebovirus, RVFV. Le May et al. [20] mapped the N-N interacting domain to the first $71 \mathrm{~N}$ terminal residues of RVFV-N protein and showed the particular importance of $\mathrm{Y} 4$ and $\mathrm{F} 11$ (corresponding to W7 and I14 of UUKV-N) for the oligomerization. Secondary structure predictions suggest a universal mode of folding for phleboviral $\mathrm{N}$ proteins, thus the oligomerization mechanism might be similar in all members of the Phlebovirus genus, and could also share some important features with other bunyaviral $\mathrm{N}$ proteins. Indeed, the very recent publication on structure of RVFV-N protein [31], suggest that due to high sequence identity, all phlebovirus $\mathrm{N}$ proteins have the same fold, which may also exist throughout the Bunyaviridae family.

Similarly to phleboviral $\mathrm{N}$ proteins, the $\mathrm{N}$ proteins of BUNV (genus Orthobunyavirus) and hantaviruses (genus Hantavirus) oligomerize in a head-to-head and tail-to- 
tail fashion, and in all three genera the $\mathrm{N}$-terminus of the $\mathrm{N}$ protein plays an important role $[16,21,22,25]$. One would expect to see some differences between the genera as well. Indeed, in hantaviruses the C-terminal part of the $\mathrm{N}$ protein plays crucial role in the oligomerization thus even point mutations introduced to this region can totally destroy the functionality of the molecule [25]. In mapping of the BUNV-N protein [21] the N-N interacting residues were located to the $\mathrm{N}$-terminal region, the middle region and the $\mathrm{C}$-terminus of the $\mathrm{N}$ protein. In contrast, in RVFV-N protein the C-terminal region was not found essential for the N-N interaction [20] and our data on UUKV showed that point mutations supposedly destroying proper folding of the last C-terminal $\alpha$-helix did not affect the $\mathrm{N}$ protein functionality (Fig. 7 and Table 1). Although deletion of the C-terminal $\alpha$-helices resulted in loss of activity in the minigenome and $\mathrm{M} 2 \mathrm{H}$ assays, this could be caused by overall misfolding of the truncated protein.

In this paper, 3D-model of UUKV-N protein predicted using an $a b$ initio approach has been proven useful to direct experiments to analyze N-N interactions. In the absence of X-ray crystallography or NMR structures of UUKV-N protein, our 3D-model might be helpful also in studying other functions of the molecule, such as RNA binding that is highly relevant to the $\mathrm{N}$ protein oligomerization, since both processes are coupled. Studies on RNA-binding properties of UUKV-N protein go beyond the frame of this project. Our preliminary data on mapping the $\mathrm{N}$ protein RNA-binding domain confirmed that predictions drawn from the model are reasonably accurate [Katz et al., MS in preparation].

Details of the UUKV-N protein oligomerization remain largely unknown. As a working hypothesis one could consider two alternative modes of interaction between specific structures formed by the $\mathrm{N}$-terminal $\alpha$ helices: (1) The interaction occurs between intact structures; in this case two interacting surfaces that are formed by aromatic and long aliphatic side chains are coming into close proximity and form a shared hydrophobic space, and (2). The interaction occurs after a conformational change that opens the structure and forms a new interacting surface mainly, or even exclusively, from the same side chains. In the above mentioned work, Raymond and co-authors [31] showed the importance of the hydrophobic residues - both in maintaining the structural stability and as sites for the N-N interaction, as we suggest in our study.

\section{Conclusions}

Our results show that UUKV-N protein has ability to form oligomers in chemical cross-linking and mammalian two-hybrid assays. This oligomerization ability depends on the presence of intact $\alpha$-helices on both termini of the molecule. Moreover, a set of $\mathrm{N}$ protein mutations were analyzed in minigenome and mammalian two-hybrid assays; this data in combination with the computer modeling suggested that a specific structure in the N-terminal region plays a crucial role in the $\mathrm{N}-\mathrm{N}$ interactions.

\section{Methods}

\section{Viruses and cells}

The origin and the preparation of the UUKV prototype strain S23 have been described earlier [32]. All cell lines were from the ATCC: BHK-21 cells were grown in Glasgow minimal essential medium (GMEM; Invitrogen), COS-7 cells in Dulbecco's modified Eagle medium (DMEM), HeLa cells in minimum essential medium (MEM), and Sf9 insect cells in SF-900 II SF medium (Invitrogen). The media were supplemented with $10 \%$ fetal bovine serum, $2 \mathrm{mM}$ L-glutamine, $100 \mathrm{IU}$ of penicillin $/ \mathrm{ml}$, and $100 \mu \mathrm{g}$ streptomycin $/ \mathrm{ml}$ and maintained at $37^{\circ} \mathrm{C}$ in a $5 \%-\mathrm{CO}_{2}$ atmosphere.

\section{Antibodies and antisera}

UUKV-N protein was detected with earlier described [28], or commercial (ProSci Inc.) rabbit polyclonal antibodies, and mouse monoclonal antibodies (MAbs) (R. F. Pettersson, unpublished data) against UUKV-N protein. The UUKV-N fusion proteins used in the M2H assay were detected using MAbs raised against GAL4 DNAbinding (DNA-BD) and/or VP16 DNA activation (DNAAD) domains (Santa Cruz Biotechnology).

\section{Plasmids}

UUKV-N mutants were derived from plasmid pGEM$3 \mathrm{~N}$ [33] containing complete UUKV-N protein cDNA. The UUKV-N ORF was amplified using $P f u$ DNA polymerase (Fermentas), digested with the restriction endonucleases HindIII and XbaI, and cloned into pcDNA3.1 $(+)$ (Invitrogen), resulting in the construct pcDNAUUKV-N encoding the full-length, wild type (wt) $\mathrm{N}$ protein. $\mathrm{N}$ - and $\mathrm{C}$-terminal truncations were introduced by oligonucleotide-directed mutagenesis using primers carrying HindIII/XbaI restriction sites. These PCR products were also cloned into the plasmids used in the $\mathrm{M} 2 \mathrm{H}$ assay: pM1, containing DNA-BD and/or pVP16 containing DNA-AD domain (BD Biosciences Clontech). Alanine substitutions were introduced into the plasmids with site-directed mutagenesis kit (Stratagene) according to the manufacturer's instructions. The accuracy cloning was verified by restriction analysis and sequencing.

\section{Structural analysis of UUKV-N protein and sequence alignments}

The secondary structure of UUKV-N protein was predicted using servers Jpred http://www.compbio.dundee. 
ac.uk/ www-jpred/[34], PsiPred http://bioinf.cs.ucl.ac. uk/psipred/[35], and PredictProtein http://www.predictprotein.org/[36]. Tertiary structure of the $\mathrm{N}$ protein was predicted using Robetta server's $a b$ initio modeling http://robetta.bakerlab.org/[37,38], and phlebovirus N protein sequences were aligned using ClustalW program http://www.ebi.ac.uk/clustalw.

\section{Chemical cross-linking}

COS-7 cells were grown to $70-80 \%$ confluence and transfected with pcDNA-UUKV-N constructs and FuGene6 reagent (Roche Applied Science) according to the manufacturer's instructions. After $24 \mathrm{~h}$ cells were washed and scraped to PBS, pH 7.4, and freeze-thawed three times. Cell lysates were cross-linked using 0.1 and $0.5 \mathrm{mM}$ bis[sulfosuccinimidyl] suberate $\left(\mathrm{BS}^{3}\right)$ (Thermo Fisher Scientific) for $30 \mathrm{~min}$ at room temperature (RT). After quenching the reaction with $50 \mathrm{mM}$ Tris- $\mathrm{HCl}, \mathrm{pH}$ 7.5 , proteins were separated on $10 \%$ SDS-PAGE. Proteins were detected by immunoblotting with a rabbit antiserum against UUKV-N protein [28], followed by incubation with horseradish peroxidase (HRP)-conjugated swine anti-rabbit IgG antibody (Dako) and visualized using the enhanced chemiluminescence (ECL) method.

\section{Mammalian two-hybrid (M2H) assay}

HeLa cells were grown to $70-80 \%$ confluence and transfected with $0.5 \mu \mathrm{g}$ of pM-UUKV-N and pVP-UUKV-N constructs expressing the full-length or mutated $\mathrm{N}$ protein, $0.5 \mu \mathrm{g}$ of the reporter-encoded plasmid pG5luc expressing the firefly luciferase (FL, Promega), and 0.01 $\mu \mathrm{g}$ of pRL-SV40 expressing Renilla luciferase (RL, Promega) to normalize the results. Each mutant was tested in triplicate $(2 \mu \mathrm{l}$ FuGene6 reagent for each reaction), and all experiments were performed at least twice. The reporter gene activities were determined 24 h posttransfection with the Dual-Luciferase Reporter Assay System (Promega). To balance inherent variations in the $\mathrm{M} 2 \mathrm{H}$ assay, the FL-values were normalized using the RL-values: Normalized value of experiment $A=[(R L-$ value from $\mathrm{N}-\mathrm{N}$ interaction/RL-value of experiment $\mathrm{A}$ ) $\times($ FL-value of experiment A)]. The formula for percent interaction $=($ normalized value of experiment $\mathrm{A} /$ normalized value of $\mathrm{N}-\mathrm{N}$ interaction) $\times 100$.

For immunoblotting, COS-7 cells were transfected with $\mathrm{M} 2 \mathrm{H}$ constructs using the FuGene6 reagent, washed at $24 \mathrm{~h}$, and lysed with the Passive Lysis Buffer (Dual-Luciferase Reporter Assay System) for $15 \mathrm{~min}$ on ice. Cell lysates were clarified and proteins were separated on 10\% SDS-PAGE under reducing conditions, and transfered to nitrocellulose membrane. Proteins were detected by incubation with MAbs recognizing DNA-BD and DNA-AD domains, followed by incubation with HRP-conjugated rabbit anti-mouse IgG antibodies (Dako), and visualized using the ECL system.

\section{Immunofluorescence assay (IFA)}

BHK-21 cells were grown on coverslips to $70-80 \%$ confluence, and either transfected with $0.5 \mu \mathrm{g}$ of wt or mutant pcDNA-UUKV-N constructs with $2 \mu \mathrm{l}$ of FuGene6 reagent, or infected with UUKV with undefined multiplicity of infection (estimate from 1 to 5 ) for $1 \mathrm{~h}$, after which the medium was replaced. At $24 \mathrm{~h}$ post-transfection and infection, cells were washed and fixed with $3 \%$ paraformaldehyde $(15 \mathrm{~min})$ and permeabilized with $0.1 \%$ Triton X-100 (30 min), both in PBS. After washing, the coverslips were incubated with two UUKV-N MAbs (30 min), followed by FITC-conjugated rabbit anti-mouse IgG antibodies (Dako) (30 min), all incubations at RT. Images were collected with Zeiss Axioplan 2 microscope.

\section{RNA Pol I-driven UUKV minigenome system}

BHK-21 cells were grown to $80 \%$ confluence and transfected with UUKV M-CAT, pCMV-UUKV-L [5], and wt or mutated pcDNA-UUKV-N, using $4 \mu \mathrm{l}$ of LipofectA$\mathrm{MINE}^{\mathrm{m}} 2000$ transfection reagent (Invitrogen) following the manufacturer's instructions. Cells were analyzed for reporter gene chloramphenicol acetyltransferase (CAT) activity $48 \mathrm{~h}$ post-transfection. The CAT assay was performed as described earlier [5], and according to the manufacturer's instructions (FAST CAT Kit; Invitrogen). Briefly, cells were harvested in PBS, resuspended in 250 $\mathrm{mM}$ Tris- $\mathrm{HCl}$ ( $\mathrm{pH}$ 7.4) and lysed by three freeze-thaw cycles. Clarified cell lysates were mixed with $9 \mathrm{mM}$ acetyl coenzyme A (Sigma Aldrich), Component A (Fast $\mathrm{CAT}$ Kit) and $250 \mathrm{mM}$ Tris- $\mathrm{HCl}(\mathrm{pH} \mathrm{7.4)}$. After 2 to $4 \mathrm{~h}$ at $37^{\circ} \mathrm{C}$, samples were prepared for thin-layer chromatography and the reaction products were visualized by UV illumination.

\section{Virus-like particle (VLP) system for UUKV}

VLP infection was performed as described earlier [30]: Briefly, supernatant of cells transfected with the abovementioned minigenome plasmids and pCMV-UUKV$G_{N} / G_{C}$ expressing the UUKV $M$ segment was transfered to BHK-21 cells. These cells were transfected with pCMV-UUKV-L and wt pcDNA-UUKV-N $24 \mathrm{~h}$ prior VLP passage to maintain replication and transcription of the transfered minigenome, thereby allowing expression of the reporter gene. After $1 \mathrm{~h}$ incubation the inoculum was replaced by fresh medium and cells were analyzed for CAT activity $48 \mathrm{~h}$ post-infection. The CAT assay was performed as described above. For immunoblotting, cells were lysed in the M-PER ${ }^{\circ}$ Reagent (Pierce), and incubated $20 \mathrm{~min}$ on ice. Cell lysates were separated by $10 \%$ SDS-PAGE and UUKV-N proteins were detected 
by immunoblotting with a rabbit polyclonal anti-UUKV$\mathrm{N}$ antibody (ProSci), followed by incubation with HRPlabeled goat anti-rabbit IgG antibody (Sigma).

\section{Acknowledgements}

This work was supported by the Helsinki Biomedical Graduate School and Sigrid Jusélius Foundation, Helsinki.

\section{Author details}

'Department of Virology, Infection Biology Research Program, Haartman Institute, P.O. Box 21, 00014, University of Helsinki, Helsinki, Finland. ${ }^{2}$ Department of Pathology, University of Texas Medical Branch, 301 University Boulevard, Galveston, TX 77555-0609, USA. ${ }^{3}$ Structural Genomics Group, Institute of Biotechnology P.O. Box 56, 00014 University of Helsinki, Helsinki, Finland. ${ }^{4}$ Ludwig Institute for Cancer Research, Stockholm Branch, Karolinska Institute, P.O. Box 240, 17177 Stockholm, Sweden. ${ }^{5}$ Software Point, Valkjärventie 1, 02130 Espoo, Finland. ${ }^{6}$ BioProtection Systems Corporation, 2901 South Loop Drive, Suite 3360, Bldg. 3, Ames, IA 50010-8646, USA.

\section{Authors' contributions}

AK and AP designed the study, AV, LH, RP and RF were involved in the study design. AK prepared recombinant plasmids and introduced all truncations and point mutations. AK, VB and LH performed bioinformatic analysis. AK performed chemical cross-linking, M2H assay, IFA, and immunoblotting for the $\mathrm{M} 2 \mathrm{H}$ constructs; $\mathrm{AF}, \mathrm{ARS}$ and $\mathrm{AM}$ performed the minigenome and VLP assays including the immunoblotting. AK, AF, VB, RF and $\mathrm{AP}$ analyzed the data. AK, AF and AP wrote the draft of the manuscript. All authors read and approved the final manuscript.

\section{Competing interests}

The authors declare that they have no competing interests.

Received: 16 June 2010 Accepted: 10 August 2010

Published: 10 August 2010

\section{References}

1. Nichol ST, Beaty BJ, Elliott RM, Goldbach R, Plyusnin A, Schmaljohn CS, Tesh RB: Family Bunyaviridae. Virus Taxonomy: Eighth Report of the International Committee on Taxonomy of Viruses London, UK: Elsevier Academic PressFauquet CM, Mayo MA, Maniloff J, Desselberger U, Ball LA 2005, 695-716

2. Oker-Blom N, Salminen A, Brummer-Korvenkontio M, Kääriäinen L, Weckström P: Isolation of some viruses other than typical tick-borne encephalitis viruses from Ixodes ricinus ticks in Finland. Ann Med exp Biol Fenn 1964, 42:109-112.

3. Saikku P, Brummer-Korvenkontio M: Arboviruses in Finland. II. Isolation and characterization of Uukuniemi virus, a virus associated with ticks and birds. Am J Trop Med Hyg 1973, 22(3):390-399.

4. Andersson AM, Pettersson RF: Targeting of a short peptide derived from the cytoplasmic tail of the G1 membrane glycoprotein of Uukuniemi virus (Bunyaviridae) to the Golgi complex. J Virol 1998, 72(12):9585-9596.

5. Flick R, Pettersson RF: Reverse genetics system for Uukuniemi virus (Bunyaviridae): RNA polymerase I-catalyzed expression of chimeric viral RNAs. J Virol 2001, 75(4):1643-1655.

6. Flick K, Katz A, Överby A, Feldmann H, Pettersson RF, Flick R: Functional analysis of the noncoding regions of the Uukuniemi virus (Bunyaviridae) RNA segments. J Virol 2004, 78(21):11726-11738.

7. Överby AK, Pettersson RF, Grünewald K, Huiskonen JT: Insights into bunyavirus architecture from electron cryotomography of Uukuniemi virus. Proc Natl Acad Sci USA 2008, 105(7):2375-2379.

8. Kaukinen P, Vaheri A, Plyusnin A: Hantavirus nucleocapsid protein: a multifunctional molecule with both housekeeping and ambassadorial duties. Arch Virol 2005, 150(9):1693-1713.

9. Becker S, Rinne C, Hofsäss U, Klenk HD, Mühlberger E: Interactions of Marburg virus nucleocapsid proteins. Virology 1998, 249(2):406-417.

10. Myers TM, Pieters A, Moyer SA: A highly conserved region of the Sendai virus nucleocapsid protein contributes to the NP-NP binding domain. Virology 1997, 229(2):322-335
11. Ortega J, Martín-Benito J, Zurcher T, Valpuesta JM, Carrascosa JL, Ortín J: Ultrastructural and functional analyses of recombinant influenza virus ribonucleoproteins suggest dimerization of nucleoprotein during virus amplification. J Virol 2000, 74(1):156-163.

12. Albertini AA, Wernimont AK, Muziol T, Ravelli RB, Clapier $C R$, Schoehn $G$, Weissenhorn W, Ruigrok RW: Crystal structure of the rabies virus nucleoprotein-RNA complex. Science 2006, 313(5785):360-363.

13. Green TJ, Zhang X, Wertz GW, Luo M: Structure of the vesicular stomatitis virus nucleoprotein-RNA complex. Science 2006, 313(5785):357-360.

14. Rudolph MG, Kraus I, Dickmanns A, Eickmann M, Garten W, Ficner R: Crystal structure of the Borna disease virus nucleoprotein. Structure (Camb) 2003, 11(10):1219-1226.

15. Ye Q, Krug RM, Tao YJ: The mechanism by which influenza A virus nucleoprotein forms oligomers and binds RNA. Nature 2006, 444(7122):1078-1082.

16. Leonard VH, Kohl A, Osborne JC, McLees A, Elliott RM: Homotypic interaction of Bunyamwera virus nucleocapsid protein. J Virol 2005, 79(20):13166-13172.

17. Alfadhli A, Love Z, Arvidson B, Seeds J, Willey J, Barklis E: Hantavirus nucleocapsid protein oligomerization. J Virol 2001, 75(4):2019-2023.

18. Kaukinen $\mathrm{P}$, Koistinen $\mathrm{V}$, Vapalahti $\mathrm{O}$, Vaheri $\mathrm{A}$, Plyusnin $\mathrm{A}$ : Interaction between molecules of hantavirus nucleocapsid protein. J Gen Virol 2001 82(Pt 8):1845-1853.

19. Snippe M, Borst JW, Goldbach R, Kormelink R: The use of fluorescence microscopy to visualise homotypic interactions of tomato spotted wilt virus nucleocapsid protein in living cells. J Virol Methods 2005, 125(1):15-22.

20. Le May N, Gauliard N, Billecocq A, Bouloy M: The N terminus of Rift Valley fever virus nucleoprotein is essential for dimerization. J Virol 2005 , 79(18):11974-11980.

21. Eifan SA, Elliott RM: Mutational analysis of the Bunyamwera orthobunyavirus nucleocapsid protein gene. J Virol 2009, 83(21):11307-11317.

22. Alminaite $A$, Halttunen $V$, Kumar $V$, Vaheri A, Holm L, Plyusnin A: Oligomerization of hantavirus nucleocapsid protein: analysis of the $\mathrm{N}$ terminal coiled-coil domain. J Virol 2006, 80(18):9073-9081.

23. Alminaite $A$, Backström V, Vaheri A, Plyusnin A: Oligomerization of hantaviral nucleocapsid protein: charged residues in the N-terminal coiled-coil domain contribute to intermolecular interactions. J Gen Virol 2008, 89(Pt 9):2167-2174.

24. Kaukinen $P$, Vaheri $A$, Plyusnin $A$ : Mapping of the regions involved in homotypic interactions of Tula hantavirus N protein. J Virol 2003, 77(20):10910-10916.

25. Kaukinen $P$, Kumar $V$, Tulimäki $K$, Engelhardt $P$, Vaheri $A$, Plyusnin A: Oligomerization of Hantavirus $\mathrm{N}$ protein: C-terminal alpha-helices interact to form a shared hydrophobic space. J Virol 2004, 78(24):13669-13677.

26. Boudko SP, Kuhn RJ, Rossmann MG: The coiled-coil domain structure of the Sin Nombre virus nucleocapsid protein. J Mol Biol 2007, 366(5):1538-1544.

27. Wang Y, Boudreaux DM, Estrada DF, Egan CW, St Jeor SC, De Guzman RN: NMR structure of the N-terminal coiled coil domain of the Andes hantavirus nucleocapsid protein. J Biol Chem 2008, 283(42):28297-28304

28. Kuismanen E, Hedman K, Saraste J, Pettersson RF: Uukuniemi virus maturation: accumulation of virus particles and viral antigens in the Golgi complex. Mol Cell Biol 1982, 2(11):1444-1458.

29. Alfadhli A, Steel E, Finlay L, Bachinger HP, Barklis E: Hantavirus nucleocapsid protein coiled-coil domains. J Biol Chem 2002, 277(30):27103-27108

30. Överby AK, Popov V, Neve EP, Pettersson RF: Generation and analysis of infectious virus-like particles of Uukuniemi virus (Bunyaviridae): a useful system for studying bunyaviral packaging and budding. J Virol 2006, 80(21):10428-10435.

31. Raymond DD, Piper ME, Gerrard SR, Smith JL: Structure of the Rift Valley fever virus nucleocapsid protein reveals another architecture for RNA encapsidation. Proc Natl Acad Sci USA 2010, 107(26):11769-11774.

32. Pettersson $R$, Kääriäinen $L$ : The ribonucleic acids of Uukuniemi virus, a noncubical tick-borne arbovirus. Virology 1973, 56(2):608-619.

33. Simons JF, Persson R, Pettersson RF: Association of the nonstructural protein NSs of Uukuniemi virus with the $40 \mathrm{~S}$ ribosomal subunit. J Virol 1992, 66(7):4233-4241. 
34. Cole C, Barber JD, Barton GJ: The Jpred 3 secondary structure prediction server. Nucleic Acids Res 2008, , 36 Web Server: W197-201.

35. Bryson K, McGuffin LJ, Marsden RL, Ward JJ, Sodhi JS, Jones DT: Protein structure prediction servers at University College London. Nucleic Acids Res 2005, , 33 Web Server: W36-8.

36. Rost B, Yachdav G, Liu J: The PredictProtein server. Nucleic Acids Res 2004, 32 Web Server: W321-6.

37. Bonneau R, Strauss CE, Rohl CA, Chivian D, Bradley P, Malmström L, Robertson T, Baker D: De novo prediction of three-dimensional structures for major protein families. J Mol Biol 2002, 322(1):65-78.

38. Chivian D, Kim DE, Malmström L, Schonbrun J, Rohl CA, Baker D: Prediction of CASP6 structures using automated Robetta protocols. Proteins 2005, 61(Suppl 7):157-166.

doi:10.1186/1743-422X-7-187

Cite this article as: Katz et al:: Oligomerization of Uukuniemi virus nucleocapsid protein. Virology Journal 2010 7:187.

\section{Submit your next manuscript to BioMed Central} and take full advantage of:

- Convenient online submission

- Thorough peer review

- No space constraints or color figure charges

- Immediate publication on acceptance

- Inclusion in PubMed, CAS, Scopus and Google Scholar

- Research which is freely available for redistribution

Submit your manuscript at www.biomedcentral.com/submit 